www.jmscr.igmpublication.org Impact Factor 5.244

Index Copernicus Value: 83.27

ISSN (e)-2347-176x ISSN (p) 2455-0450

crossref DOI: _https://dx.doi.org/10.18535/jmscr/v4i10.56

Journal Of Medical Science And Clinical Research

\title{
Hematological Profile in Patients Suffering From Tuberculosis and Treatment Response
}

\author{
Authors \\ Saket Kumar Mandal ${ }^{1}$, Laxmikant Chavan ${ }^{2}$ \\ ${ }^{1}$ MBBS, DNB (General Medicine), Resident Physician, Jurong Heath, Singapore \\ ${ }^{2}$ MBBS, MD (Internal Medicine), Medical Superintendent Class I / Specialist Physician, Sub District \\ Hospital, Karjat
}

\section{ABSTRACT}

Background: Reversible peripheral blood abnormalities are commonly associated with pulmonary tuberculosis and these hematological changes act as marker for the diagnosis, prognosis and response to therapy. There is no comprehensive study assessing the haematological abnormalities in these patients from the Indian subcontinent. The present study has been an attempt to investigate hematological changes in patients with active pulmonary and extrapulmonary TB. An attempt has also been made to assess the effect of six months antituberculosis therapy on the haematologic abnormalities.

Material \& Methods: The study subjects included 100 patients above 12 years of age without HIV coinfection of newly diagnosed cases of pulmonary and extrapulmonary tuberculosis diagnosed. For haematological analysis, about 3-4 ml peripheral venous blood was drawn aseptically with the help of sterile syringe. Two $\mathrm{ml}$ was transferred into a tube containing $0.2 \mathrm{ml}$ of $4 \%$ EDTA solution and analyzed in the Hematology Analyzer for evaluation of different blood parameters. The remaining $2 \mathrm{ml}$ of the blood were used for ESR determination.

Results: Out of the 100 cases of tuberculosis collected from our hospital, 55 patients were PTB, and 45 were of extra-pulmonary tuberculosis. Anemia was identified in 71 patients $(71 \%)$ at the time of diagnosis of TB. In 38 patients, the hemoglobin concentration was less than $10 \mathrm{~g} / \mathrm{dL}$. Mean ESR in all patients was $67.6 \mathrm{~mm} / \mathrm{hr}$ with no statistically significant difference between pulmonary, extra-pulmonary and disseminated TB. The WBC count presented variable features. Total leukocytes count was lower than normal in 5 (7.8\%) and 3 (8.8\%), while lymphocytopenia in $37(57.8 \%)$ and 14 (41.2\%) in male and female patients respectively. Thrombocytopenia were observed in $9(14 \%)$ and $4(11.8 \%)$ in male and female patients respectively.

Discussion: Some haematological abnormalities are quite common in patients with pulmonary TB and physicians must maintain a high index of suspicion for diagnosis of pulmonary TB in patients with these abnormalities.

Keywords: Tuberculosis, haematological abnormalities, diagnosis, prognosis.

\section{INTRODUCTION}

Tuberculosis (TB) is highly prevalent chronic devastating disease caused by Mycobacterium tuberculosis present globally especially in the developing countries including India. Despite the advances and the fact that nearly all cases can be cured, TB remains one of the world's biggest threats. In 2014, TB killed 1.5 million people (1.1 million HIV-negative and 0.4 million HIV-positive). The 
toll comprised 890000 men, 480000 women and 140000 children $^{[1]}$.

Reversible peripheral blood abnormalities are commonly associated with pulmonary tuberculosis and these hematological changes act as marker for the diagnosis, prognosis and response to therapy. TB cause profound bone marrow and peripheral blood abnormalities by modulating normal hematopoiesis and the disease become more severe when it is co-infected with HIV because of weakened immunity ${ }^{[2]}$. In pulmonary tuberculosis many hematological and biochemical abnormalities are common and they are valuable aids to diagnosis. A variety of haematological changes have been described in patients with tuberculosis such as anemia, increased erythrocyte sedimentation rate, low serum albumin level and leukocytosis ${ }^{[3]}$.

In active TB cases, anemia and iron deficiency erythropoiesis was observed. A close relationship was found to be exist between severity of tuberculosis and hematological abnormalities. During antituberculous treatment improvements in the hematological values such as, rise in hemoglobin and hematocrit values, were used as indicators reflecting good response to the treatment ${ }^{[4]}$. Furthermore, fall in values of platelet, white cell and erythrocyte sedimentation rate (ESR) were regarded as markers of good disease control ${ }^{[5]}$.

The comprehensive investigations on hematological changes and abnormalities associated with tuberculosis have been incompletely investigated. There is no comprehensive study assessing the haematological abnormalities in these patients from the Indian subcontinent. The present study has been an attempt to investigate hematological changes in patients with active pulmonary and extrapulmonary TB. An attempt has also been made to assess the effect of six months antituberculosis therapy on the haematologic abnormalities.

\section{MATERIAL AND METHODS}

The study subjects included 100 patients of newly diagnosed active cases (defined as up to two weeks after the start of antituberculous treatment) of pulmonary and extra-pulmonary tuberculosis diagnosed between October 2006 to October 2008 in the Medicine and Chest TB department of Mahatma Gandhi Mission's Medical College, New Mumbai.

The inclusion criteria were patients first time diagnosis, no current or previous anti-tuberculous drug treatment, and not to be suffering from any other chronic disease. The exclusion criteria included past history of pulmonary TB, currently on antituberculous drug or any other drugs which affected bone marrow or peripheral blood, and known at the time of study to have a chronic disease which will adversely affect the body systems including the bone marrow and the peripheral blood.

Depending on the site/s involved, TB was classified as pulmonary or extra-pulmonary as per WHO guidelines ${ }^{[6]}$ and disseminated if the patient had miliary TB or involvement of two or more organ systems. Detailed clinical history and physical examination was done of all the enrolled patients. Pulmonary TB patients were diagnosed on the basis of positive sputum smears for acid fast bacilli (AFB), and /or radiographic reports, skin tests and positive culture reports. For extra pulmonary $\mathrm{TB}$, detection of AFB in the samples, radio-imaging reports, skin tests and positive culture reports were taken into account. Data was collected pertaining to demographics and past history of contact with, or treatment for TB, Skin test results, bacteriologic studies, radiographic reports, and symptoms upon presentation were also assessed for each subject.

For haematological analysis, about 3-4 $\mathrm{ml}$ peripheral venous blood was drawn aseptically with the help of sterile syringe. Two $\mathrm{ml}$ was transferred into a tube containing $0.2 \mathrm{ml}$ of $4 \%$ Ethylene diamine tetra acetic acid (EDTA) solution and analyzed in the Hematology Analyzer for evaluation of different blood 
parameters. The remaining $2 \mathrm{ml}$ of the blood were used for Erythrocytic sedimentation rate (ESR) determination. Approximately $02 \mathrm{ml}$ of the anticoagulant added blood was drawn into a Westergen tube up to the mark. The tube was placed in a stand vertically for one hour and the readings were recorded.

\section{RESULTS}

A total of 100 patients newly diagnosed as pulmonary and extra pulmonary TB were enrolled in this present study. Of the 100 patients, 63 $(63 \%)$ were under 40 years of age (range 12 to $39)$, whereas, 37 (37\%) were more or equal to 40 years of age (range 40 to 78 ). Mean age of young adults (below 40 years) was $32.71 \pm 3.7$ years \& elderly (more than or of 40 years) was $67.57 \pm 1.03$ respectively.

\section{Blood Parameters}

Haemoglobin Concentration: Anemia was identified in 71 patients $(71 \%)$ at the time of diagnosis of TB. 43 of 64 (67.18\%) men and 28 of $36(77.77 \%)$ women with TB had anemia. In 38 patients, the hemoglobin concentration was less than $10 \mathrm{~g} / \mathrm{dL}$. No male patient had a hemoglobin concentration less than $6.9 \mathrm{~g} / \mathrm{dL}$ although 4 female patient had a hemoglobin concentration less than $6.9 \mathrm{~g} / \mathrm{dL}$ (Table 1). Normocytic and normochromic anemia was most common, and was identified in 51 of $71(71.83 \%)$ anemic patients; and microcytic hypochromic anemia was next common (14 patients, 19.71\%). The presence of anemia was associated with age older than 62 years and female sex.

Table 1: Distribution of hemoglobin concentrations in patients with tuberculosis

\begin{tabular}{|l|c|c|c|}
\hline $\begin{array}{l}\text { Hemoglobin } \\
\text { concentration }\end{array}$ & Male & Female & Total \\
\hline$<6.9$ & 00 & 04 & 04 \\
\hline $7.0-9.9$ & 16 & 18 & 34 \\
\hline $10.0-11.9$ & 11 & 06 & 17 \\
\hline $12-12.9$ & 16 & 03 & 19 \\
\hline$>13.0$ & 21 & 05 & 27 \\
\hline
\end{tabular}

Erythrocyte sedimentation rate (ESR): ESR was elevated in $87(87 \%)$ and normal in $26(26 \%)$ of these patients. Mean ESR in all patients was 67.6 $\mathrm{mm} / \mathrm{hr}$ with no statistically significant difference between pulmonary, extra-pulmonary and disseminated TB with $\mathrm{p}=0.50$ (Table 2 ).

Table 2: ESR in patients with different types of tuberculosis

\begin{tabular}{|l|c|c|c|c|}
\hline Types of TB & $\begin{array}{c}\text { Number } \\
(\%)\end{array}$ & $\begin{array}{c}\text { Mean } \\
\text { ESR }\end{array}$ & SD & $\begin{array}{c}\text { Median } \\
\text { ESR }\end{array}$ \\
\hline Pulmonary TB & $55(55 \%)$ & 71.77 & 36.026 & 73 \\
\hline $\begin{array}{l}\text { Extra } \\
\text { pulmonary TB }\end{array}$ & $34(34 \%)$ & 65.57 & 35.027 & 59 \\
\hline $\begin{array}{l}\text { Disseminated } \\
\text { TB }\end{array}$ & $11(11 \%)$ & 65.51 & 35.309 & 69 \\
\hline Total & $100(100 \%)$ & 67.62 & 34.656 & 70 \\
\hline
\end{tabular}

Twenty-three (23\%) patients had ESR $100 \mathrm{~mm} / \mathrm{hr}$ or more while $77(77 \%)$ had ESR $<100 \mathrm{~mm} / \mathrm{hr}$. ESR below 100 or $100 \mathrm{~mm} / \mathrm{hr}$ or more in patients with different types of TB.

Leukocytes: The WBC count presented variable features. Total leukocytes count was lower than normal in $5(7.8 \%)$ and $3(8.8 \%)$, while lymphocyte-penia in $37(57.8 \%)$ and 14 (41.2\%) in male and female patients respectively. Neutrophilia was observed in $41(64.1 \%)$ and 20 $(58.8 \%)$ while neutropenia in $2(3.1 \%)$ and 1 $(2.9 \%)$ of the male and female subjects correspondingly.

\section{Thrombocytes:}

Although platelet count was found in the normal range in most of the patients, however thrombocytopenia were observed in $9(14 \%)$ and 4 $(11.8 \%)$ while thrombocytosis in $7(10.9 \%)$ and 2 $(5.9 \%)$ in male and female patients respectively.

\section{DISCUSSION}

Haematological and biochemical abnormalities in pulmonary tuberculosis are common and may be valuable aids in diagnosis. Various studies have shown anemia to be one of the commonest manifestation of $\mathrm{TB}{ }^{[7,8]}$. However, the reported incidences have varied widely from 16-94\% of patients with PTB, although, different definitions of anemia were probably applied and the cases were not necessarily freshly diagnosed. Anemia 
occurred in $71 \%$ of our patients, however, TBassociated anemia completely resolved with antiTB treatment in $64.5 \%$ of patients. In addition, the anemia improved considerably in the other patients. All chronic infections including TB can cause anemia ${ }^{[9]}$. Although a normocytic, normochromic anemia was most common in this study, other types of anemia, including hypochromic microcytic anemia, were not rare. Female sex and old age were risk factors for TBassociated anemia in our data.

In this study of newly diagnosed cases of active $\mathrm{TB}$, we found that ESR was elevated in $87 \%$ and normal in $26 \%$ of the patients. The mean ESR in pulmonary TB patients was found to be 71.77 . In a study, conducted in India, authors concluded that it probably holds true that a lower ESR value in a TB case might be associated with HIV infection in a developing country such as India, and that the higher the ESR value the lower the chance of associated HIV infection ${ }^{[10]}$. The findings of our study tend to suggest that active TB is associated mostly with very high ESR values $(\geq 100 \mathrm{~mm} / \mathrm{h})$. In patients with suggestive features of TB but without any other underlying disease affecting the ESR, the baseline ESR may be a valuable diagnostic test to suspect TB in resource poor countries.

Patients with tuberculosis had significant lymphopoenia associated with anaemia, neutrophilia and monocytosis. None of these derangements correlated with radiological extent of lung disease or cutaneous tuberculin reactivity. Lymphocyte counts returned to normal within 2 weeks of initiating chemotherapy in all lymphopoenic patients and normal ranges for all blood counts were restored by 6 months in all the patients studied. In a smear-negative patient, a clinical diagnosis of tuberculosis would be supported by the finding of lymphopoenia, not lymphocytosis. This finding is in accordance with former study in which increased numbers of neutrophils and lymphocytes in TB patients were reported in Ibadan, Nigeria ${ }^{[11]}$.
Thrombocytopenia and thrombocytosis was also observed in most of the patients in our study, as reported earlier by Olaniyi and Akeuova and Hungund et al ${ }^{[11,12]}$. Thrombocytosis is assumed to be due to increased thrombopoietic factors as an inflammatory response. Varied mechanisms like drugs immune mechanisms, bone marrow fibrosis and hypersplenism have all been implicated as possible causal factors for thrombocytopenia. Interleukin- 6 has also been regarded as potent thrombotic factor released by inflamed cells.

There was elevated level of ESR in all the patients to substantial level whereas Haemoglobin $(\mathrm{Hb})$ was lower in most of the patients presenting anaemic situation. The WBC exhibited varying degree of alteration with neutropenia and lymphopenia. The platelet count was also lower than normal in most of the patients. Some haematological abnormalities are quite common in patients with pulmonary TB and physicians must maintain a high index of suspicion for diagnosis of pulmonary $\mathrm{TB}$ in patients with these abnormalities. However, these parameters can be used as indicators in the assessment of response to chemotherapy. In view of the varied haematological abnormalities observed in patients with tuberculosis in patients of this geographical location. We suggest the differential diagnosis of tuberculosis should be entertained in patients with varied haematological disorders and effective awareness programmes should be launched in rural areas to minimize the chances of spread of the disease.

\section{Source of funding: Nil \\ Conflict of interest: None to declare}

\section{REFERENCES}

1. WHO, Global tuberculosis report. 2015:2.

2. Schlossberg D. Tuberculosis and non tuberculous mycobacterial infection.4th Edn. Saunders, Philadelphia Publisher. 1999. 
3. Charles M, Arthur B, Neel H. The Hematological and Biochemical Changes in Severe Pulmonary Tuberculosis. Q J Med. 1989;73(272):1151-1159.

4. Singla R, Al-Sharif N, Al-Sayegh M. Prevalence of resistance to antituberculosis drugs in Riyadh and a review of previous reports. Ann Saudi Med 2003a;23:143-147.

5. Morris CW, Bird AR, Nell H. The haematological and biochemical changes in severe pulmonary Tuberculosis. Q J Med 1989;73(272):1151-1159.

6. World Health Organization (2006 a). Global tuberculosis control: Surveillance, planning and financing. Geneva, Switzerland: WHO; 2006. Publication WHO/ HTM/ TB/2006.362.

7. Choi CW, Lee J, Park KH, Yoon SY, Choi IK, Oh SC, Seo JH, Kim BS, Shin SW, Kim YH, Kim JS. Prevalence and characteristics of anemia in the elderly: cross-sectional study of three urban Korean population samples. Am J Hematol 2004; 77: 26-30.

8. Ania BJ, Suman VJ, Fairbanks VF, Melton LJ 3rd. Prevalence of anemia in medical practice: community versus referral patients. Mayo Clin Proc 1994; 69: 730-5.

9. Weiss G. Pathogenesis and treatment of anaemia of chronic disease. Blood Rev 2002; 16: 87-96.

10. Shah S, Whalen C, Kotler DP, Mayanja H, Namale A, Melikian G, Mugerwa R, Semba RD. Severity of human immunodeficiency virus infection is associated with decreased phase angle, fat mass and body cell mass in adults with pulmonary tuberculosis infection in Uganda. J Nutr. 2001;131:2843-7.

11. Olaniyi JA, Akeuova YA. Hematological pro le in patients with pulmonary tuberculosis in Idaban Nigeria. Afri J Med Sci. 2003;32(3):239-242.
12. Hungund BR, Sangolli SS, Bannur HB. Blood and bone marrow ndings in tuberculosis in adults-A cross sectional study. AlAmeen J Med Sci. 2012;5 (4):362-366. 